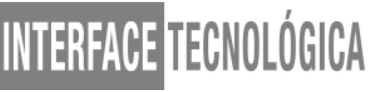

\section{A UTILIZAÇÃO DO SOFTWARE ARENA NA OTIMIZAÇÃO DE PROCESSOS DE DESCARGA DE MERCADORIAS}

\author{
THE USE OF ARENA SOFTWARE IN THE OPTIMIZATION OF UNLOADING \\ PROCESSES
}

Rafael Zucente Pereira - rafaelzucente@ hotmail.com

Rhadler Herculani - rhadler.herculani@ fatecbb.edu.br

Faculdade de Tecnologia de Bebedouro (FATEC) -SP - Brasil

DOI: 10.31510/infa.v16i2.643

\section{RESUMO}

Como as empresas brasileiras possuem inúmeras dificuldades em manter um processo logístico operando perfeitamente e gerando os menores custos possíveis, demonstrou-se, através de um software de simulação, que os mesmos podem ser úteis, apontando soluções cabíveis para a otimização de processos de descarregamento de cargas, levando em consideração: Tempos de espera, descarga, conferência dos produtos, e os tempos para guardar esses produtos no local adequado. O objetivo desse artigo é de simular situações para possíveis melhorias em um sistema de distribuição de uma determinada indústria de pães congelados de Bebedouro, interior de São Paulo. Foram utilizados métodos quantitativos de pesquisas e estudos de tempos. Existem hoje vários softwares que realizam simulações, muito pela grande demanda no momento, as empresas buscam cada vez mais esses recursos, entre esses softwares está o ARENA. Conclui-se que, ao se utilizar o software ARENA, pôde-se identificar o gargalo dos processos de separação/descarga e guardar produto da logística da referida empresa.

Palavras-chave: Simulação. Tempos. Pães congelados.

\begin{abstract}
As Brazilian companies offer the best practices to maintain a process of data processing and generate the best possible values, demonstrating through a simulation software that they are useful, pointing out solutions for an optimization of data processing processes. loads, taking into consideration: Wait times, discharge, communication of products, and times to save these products in the appropriate place. The same article is simulated in order to publish a distribution system of a single frozen bread industry in Bebedouro, in the interior of São Paulo. It was utilizated research quantitative methods and time studies. Today there are several softwares that carry out simulations, much of it in great demand at the moment, as companies increasingly seek these resources, among the software is ARENA. It concludes that, when using the ARENA software, the bottleneck of the separation / unloading processes and the company's logistics logistic of the company were identified.
\end{abstract}

Keywords: Simulation. Times. Frozen bread. 


\section{INTRODUÇÃO}

$\mathrm{O}$ atual estudo tem o objetivo de simular situações para possíveis melhorias em um sistema de distribuição de uma determinada empresa de produtos congelados do interior de São Paulo, a mesma não possui estrutura e setor de logística capacitado para um diagnóstico detalhado afim de detectar e corrigir gastos excessivos nos custos logísticos de transporte. Para Fleury (2002) o transporte é um dos principais componentes de um sistema logístico. O método de simulação através do programa ARENA pode ser de extrema importância já que a empresa busca uma redução nos custos de entrega de seus produtos, começando os estudos de tempos de clientes aleatórios, com maior tempo decorrido de entrega. De acordo com Oliveira e Sena (2007), para que o transporte rodoviário apresente bons resultados e índices de retorno aceitáveis, agregando valor ao produto transportado, é necessário que seja muito bem administrado. Já para Bowersox e Closs (2001), os sistemas de transporte são de extrema importância pois tem a capacidade de controlar os fluxos de recursos, produtos e mercadorias ao longo da cadeia de suprimentos.

Com o passar dos anos pode-se ver cada vez mais as empresas buscando uma excelência na administração do setor logístico no intuito de enxugar os gastos e extrair o máximo de lucro para assim ser mais competitivo no mercado, agregando valor e qualidade ao produto transportado.

Sendo assim, também cresce a demanda por ferramentas que possam garantir qualidade para produtos e serviços prestados, permitindo que empresas façam frente ao concorrido e crescente mercado. Para que esse atual projeto apresente soluções para os problemas apresentados, será usado a simulação computacional. Embora ainda seja limitado no Brasil a simulação busca representar a realidade através de modelos, testando alternativas e assim chegando a melhores decisões.

\section{FUNDAMENTAÇÃO TEÓRICA [TÍTULO DA SEÇÃO]}

Para Pedgen, Shannon e Sadowski (1990) a palavra simulação é definida como uma projeção computadorizada de um processo existente, a fim de entender o comportamento dos mesmos e traçando estratégias operacionais com o intuito de melhorias. 


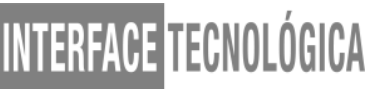

\subsection{Teoria de Simulação}

Nos dias de hoje, com o avanço tecnológico, se tornou muito comum a utilização de métodos como a simulação, facilitando e auxiliando nas tomadas de decisões difíceis e arriscadas, pois apresenta confiança e mais certeza.

De acordo com Michaelis (2016), simular é reproduzir algum processo ou situação com a maior exatidão possível.

Paragon (2005), salienta que devido ao aumento da competitividade no mercado, a simulação se tornou uma poderosa e indispensável ferramenta, auxiliadora no planejamento, nos projetos e controle de sistemas. É considerada umas ferramentas mais utilizadas para análises de projetos, operações e processos, pois essa técnica é uma ferramenta de caráter quantitativa de alto nível de confiabilidade dos sistemas em estudo.

\subsection{O Software ARENA}

Existem hoje vários softwares que realizam simulações, muito pela grande demanda no momento, as empresas buscam cada vez mais esses recursos, entre esses softwares está o ARENA. Pertence a Rockwell Software, utilizada para realizar simulações de modo lógico e muito dinâmico, determinando melhorias de condições de operação como: gargalos, visualizar filas, tempos de espera, ocupações de recursos e comportamento do sistema.

Segundo Paragon (2019), "o software ARENA é a ferramenta para simulação de eventos discretos mais usada no mundo". O software possui ambiente gráfico integrado, interface e linguagem simples, possui análises estatísticas, modelagem de processos e de resultados.

\subsection{Módulos básicos do ARENA}

Segundo Paragon (2005), o ARENA possui templates, que são módulos que compõem a criação escolhida, são conjuntos de elementos que ajudam a desenhar os processos por meio de fluxogramas que simulam os cenários desejados.

Os templates segundo Paragon (2005): 


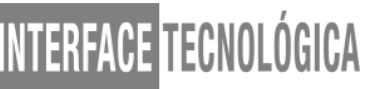

Figura 1 - Exemplo de módulos do ARENA

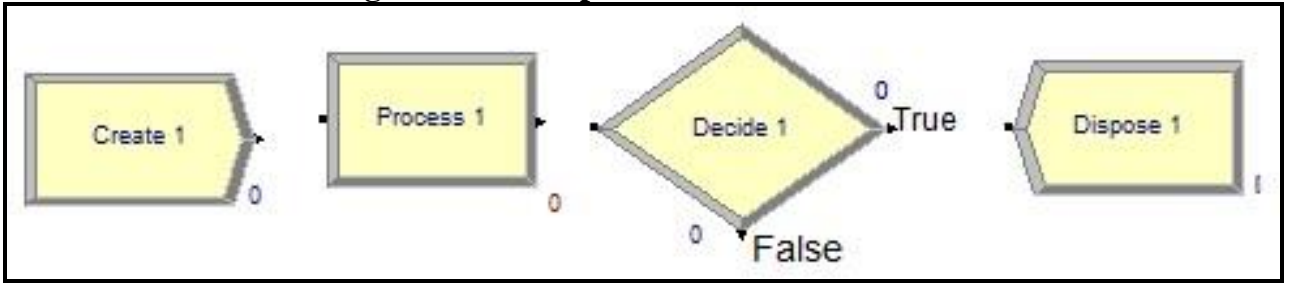

Fonte: dos autores

- Módulo Create: Onde cria-se as entidades para a simulação;

- Módulo Process: As entidades permanecem pelo tempo de duração das atividades;

- Módulo Decide: É utilizado quando, em um ponto de fluxo, existem várias opções de continuação;

- Módulo Dispose: Onde retira-se as entidades do sistema.

Prado (2014) salienta que, a coleta de dados pertencentes ao modelo é feita pelos módulos, porém não são inseridas na área de trabalho.

Após a montagem do modelo, roda-se o software e, a partir da simulação obtida, relatórios de vários formatos são gerados.

Segundo Prado (2014), no presente artigo científico foi utilizado os seguintes relatórios:

- Queues: Mostra os tempos das filas e quantidades de entidades em cada fila;

- Resources: Mostra a utilização máxima, média e mínima de cada recurso.

Segundo Prado (2014), cada projetista deve verificar cada relatório com a sua devida relevância para a contribuição nas tomadas de decisão.

Conforme Prado (2014, p. 51) além das ferramentas citadas, existe outros dois instrumentos que são definidos pelo próprio como:

- Input Analyzer: Permite a análise dos dados reais, definindo a melhor distribuição estatística, sendo encorpada diretamente no módulo.

- Output Analyzer: (Análise dos resultados) Instrumento que permite a análise dos dados coletados durante a simulação. Esta análise pode ser gráfica, podendo também realizar comparações estatísticas. 


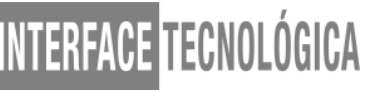

\section{PROCEDIMENTOS METODOLÓGICOS}

No presente artigo, foram utilizados métodos quantitativos de pesquisas e estudos de tempos. Utilizando os tempos e números de clientes aleatórios que apresentam maiores tempos de desperdício de tempo, como espera e o processo de guardar os produtos no local designado. A empresa se sedia em Bebedouro-SP, foi fundada em 1999 e trabalha no ramo de produtos alimentícios, no caso pães congelados.

Foram analisados e colhidos os tempos de todos os processos presentes em um processo de entrega dos produtos, como: espera para o descarregamento, separação/descarregamento, conferência dos produtos e guardar o produto no local adequado. O processo de entrega é realizado por dois funcionários e conferido por uma pessoa.

Foram colhidos 38 tempos de cada processo descrito anteriormente, utilizando cronômetro de hora centesimal, para aplicá-los no software ARENA e assim obter os relatórios necessários para os estudos. Os tempos ficaram divididos conforme o Quadro 1.

\subsection{Acompanhamento estatístico dos dados}

Como já foi mencionado, o processo de descarregamento das mercadorias é dividido em 4 processos diferentes, que juntos formam toda a atividade realizada para a entrega dos produtos ao cliente designado.

Para realizar a retirada dos tempos, foram escolhidos os próprios funcionários do setor (Motorista/Ajudante), o tempo dos processos foram retirados de cliente aleatórios com quantidade de produtos diversos, os tempos foram:

- $\quad$ Espera para o Descarregamento: entre 0 e 30 minutos por cliente;

- Separação e descarga: entre 4 e 32 minutos;

- Conferência dos produtos: entre 0,46 e 9 minutos;

- Guardar os produtos: entre 4 e 28 minutos.

Para o processamento de tempos de cada processo, foi utilizada ferramenta Input Analyser, acoplada ao Software, inserindo os tempos em sua base de dados e calculando a expressão estatística para posteriormente ser lançado no ARENA. 


\section{WNEREFAEETEECNOLOGGCA}

Quadro 1: Planilha dos tempos de cada processo

\begin{tabular}{|c|c|c|c|c|}
\hline & Espera & Separação/Descarga & Conferência & Guardar Produto \\
\hline 1 & 30,5 & 5,17 & 1,05 & 15,25 \\
\hline 2 & 24,22 & 23,11 & 2,06 & 8 \\
\hline 3 & 10,73 & 6,13 & 3,05 & 18 \\
\hline 4 & 5,5 & 8,92 & 8,13 & 13,96 \\
\hline 5 & 15 & 12,73 & 9,03 & 7 \\
\hline 6 & 22,5 & 4,57 & 7,91 & 15,55 \\
\hline 7 & 2,2 & 6,09 & 1,06 & 9,15 \\
\hline 8 & 22 & 11,68 & 5,48 & 21,01 \\
\hline 9 & 0 & 10,18 & 3,05 & 15,02 \\
\hline 10 & 21,75 & 15,05 & 3,25 & 20,55 \\
\hline 11 & 0 & 7,17 & 1,93 & 15,16 \\
\hline 12 & 14 & 10 & 3,25 & 8,73 \\
\hline 13 & 15,23 & 4,65 & 5 & 18,2 \\
\hline 14 & 3,6 & 32 & 8,21 & 22 \\
\hline 15 & 4,35 & 9.35 & 3,7 & 16,2 \\
\hline 16 & 18,87 & 8,12 & 2,18 & 18,98 \\
\hline 17 & 26,53 & 10,57 & 3,13 & 15 \\
\hline 18 & 0 & 5,23 & 3,81 & 7,13 \\
\hline 19 & 22,18 & 13,63 & 5,48 & 21,55 \\
\hline 20 & 10 & 30,03 & 3,76 & 28,8 \\
\hline 21 & 14,68 & 6,61 & 0,91 & 5,63 \\
\hline 22 & 24,72 & 25,68 & 2,05 & 11,93 \\
\hline 23 & 38,25 & 20,05 & 4,35 & 20,1 \\
\hline 24 & 6,97 & 18,73 & 5,18 & 22,8 \\
\hline 25 & 15,12 & 8,67 & 1,45 & 8,18 \\
\hline 26 & 30,38 & 16,87 & 1,76 & 21,37 \\
\hline 27 & 4,62 & 25,4 & 4,03 & 12,45 \\
\hline 28 & 18,48 & 6,63 & 1,03 & 28,15 \\
\hline 29 & 26,13 & 22,15 & 2 & 10,48 \\
\hline 30 & 27,53 & 25,48 & 2,5 & 19,4 \\
\hline 31 & 2,93 & 17,55 & 1,08 & 18,52 \\
\hline 32 & 16,22 & 26,35 & 0,78 & 12,75 \\
\hline 33 & 25,95 & 14,31 & 1,21 & 11,3 \\
\hline 34 & 6,13 & 16,15 & 3 & 8 \\
\hline 35 & 29,95 & 30,56 & 1,46 & 12,52 \\
\hline 36 & 18,32 & 7,95 & 0,46 & 4,98 \\
\hline 37 & 10,38 & 17 & 2,56 & 11,03 \\
\hline 38 & 20 & 8,05 & 1,31 & 5,37 \\
\hline
\end{tabular}

Fonte: Elaborado pelos autores

\subsection{Processamento tempo de espera}

O processo de espera é o início, se designa desde o momento de chegada no cliente, entrega da NF para o funcionário designado, lançamento da NF no sistema, verificação do arquivo de XML da NF, e então a espera para o descarregamento dos produtos, se for o caso. Com uma variação de 0 a 30 minutos e um total de 38 tempos, a expressão gerada foi: -0.001 $+39 * \operatorname{BETA}(1.05,1.51)$ conforme a Figura 2. 


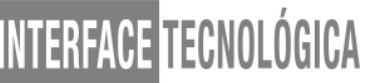

\subsection{Processamento tempo de separação e descarga}

O seguinte processo é realizado por dois funcionários, a separação e a descarga são realizadas simultaneamente, e varia muito de acordo com a quantidade e mix de produtos que os clientes compram, quanto maior o mix, e a quantidade, maior o tempo deste processo. Com uma variação de 4 a 32 minutos e um total de 38 tempos, a expressão gerada foi: $4+28$ * BETA $(0.644,1.08)$ conforme a Figura 3.

Figura 2 - Tempos de espera

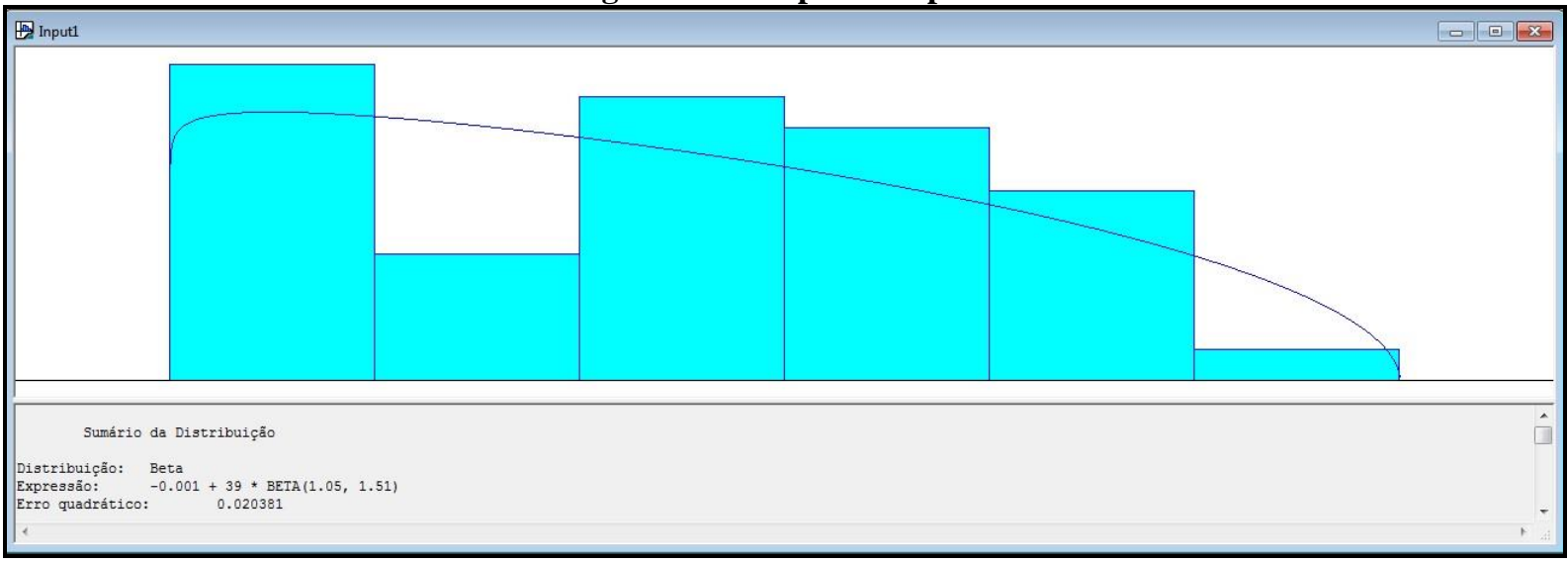

Fonte: Elaborado pelos autores

Figura 3 - Tempos de separação e descarga

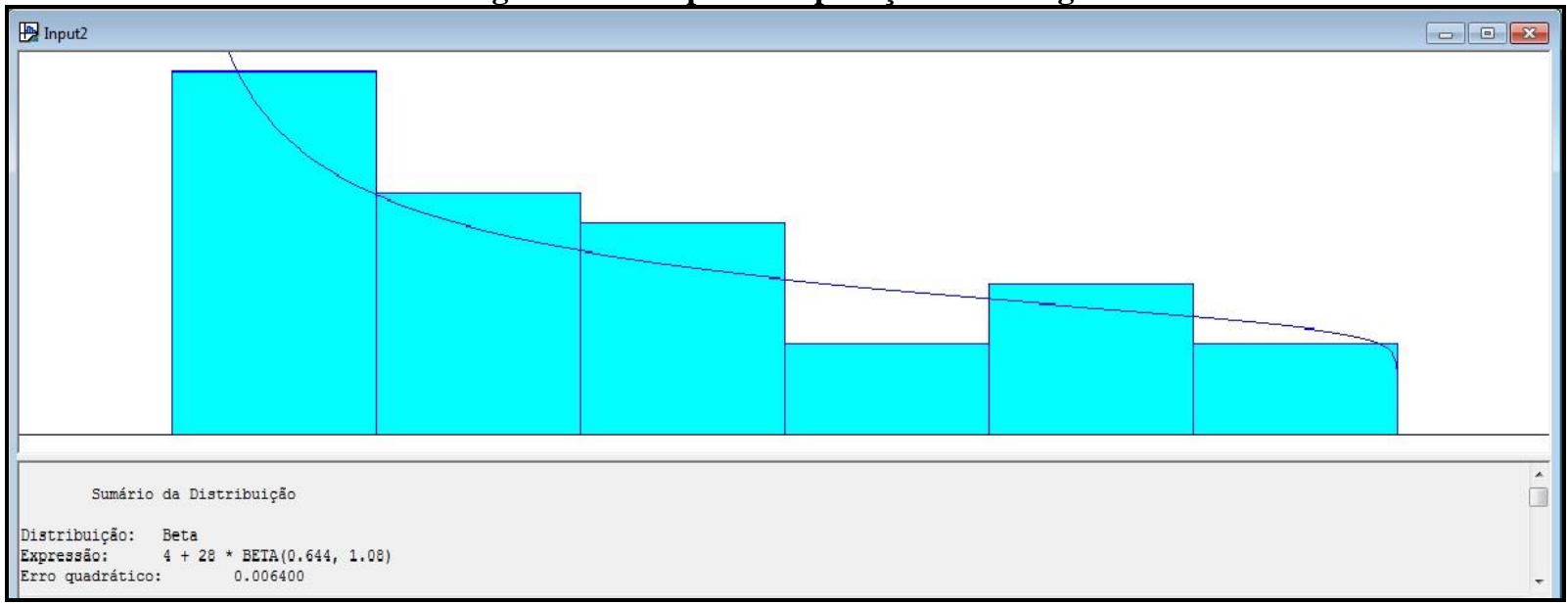

Fonte: Elaborado pelos autores

\subsection{Processamento Tempos de Conferência}

O seguinte processo é realizado por um funcionário do estabelecimento visitado, no caso conferente ou responsável pelo respectivo setor. 


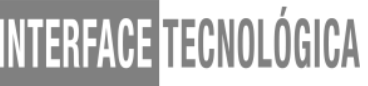

Os tempos desse processo variam muito de acordo com o grau de rigidez do estabelecimento, como por exemplo, existem estabelecimento que só realizam conferência de quantidade e código dos produtos, já outros estabelecimentos realizam vários tipos de conferência como: data de fabricação, validade, peso do produto, qualidade, entre outros. Com uma variação de 0,46 e 9 minutos, a expressão gerada foi LOGN $(3.25,2.66)$.

\subsection{Processamento tempos para guardar os produtos}

Este processo é o último antes de partir para o próximo cliente, a empresa determina que os funcionários devem guardar o produto entregue de modo que mantenha a integridade física e qualidade do mesmo, esse tempo varia de acordo com o espaço físico que o cliente tem para armazenamento, com uma variação de 4 e 28 minutos a expressão gerada foi: $4+25$ * BETA $(1.29,1.71)$.

\section{RESULTADOS E DISCUSSÃO}

Baseado na simulação realizada no software ARENA, obteve-se o seguinte layout da Figura 4.

Figura 4 - Simulação rodada no Software ARENA

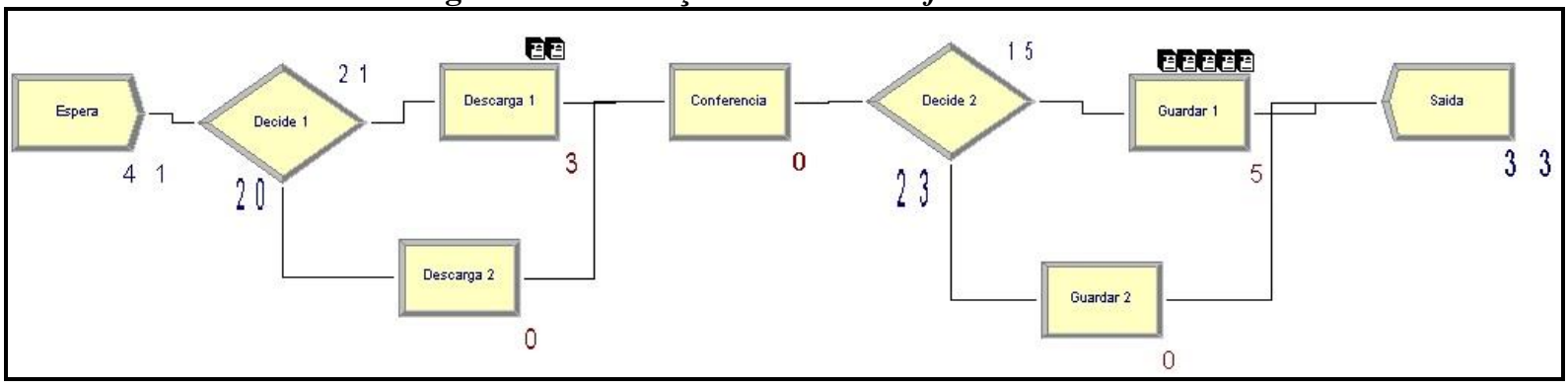

Fonte: Elaborado pelos autores

A Figura 5 representa a simulação dos processos de descarga de mercadorias em clientes aleatórios, apresentando fila nos processos de separação/descarga e guardar produto.

Pode-se identificar que em uma entrada de 41 lotes, ouve um gargalo de 3 lotes na separação/descarga e de 5 no processo de guardar produto.

Nas Figuras 5 e 6, tem-se a quantidade de filas em cada processo e a utilização dos funcionários nos respectivos processos. 
Figura 5 - Relatório de filas (Queues)

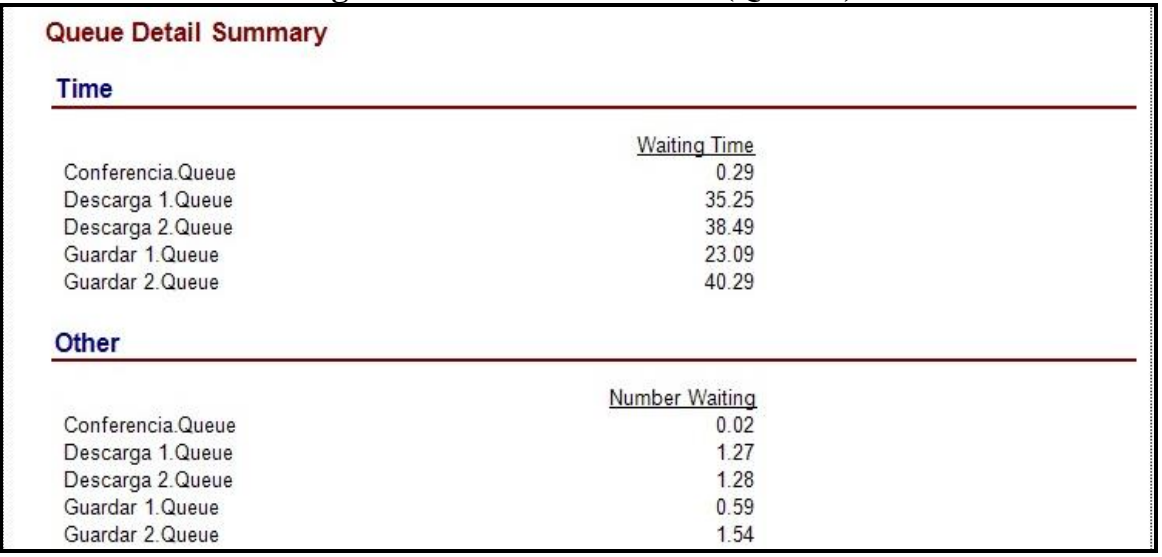

Fonte: Elaborado pelos autores

Pode-se notar que no processo de separação/descarga a fila é de 35.25 na descarga 1(motorista) e 38.49 na descarga 2 (ajudante). Já no processo de guardar os produtos a fila é de 23.09 para guardar 1(motorista) e 40.29 para guardar 2 (ajudante). A utilização do Ajudante foi de $94 \%$ (ou 0,94 no relatório de recursos da figura 8), o Conferente foi de $24 \%$ e o motorista, de $71 \%$.

Figura 6 - Relatório de recursos (Resources)

\begin{tabular}{|c|c|c|c|c|c|}
\hline \multicolumn{6}{|c|}{ Resource Detail Summary } \\
\hline & Inst Util & Num Busy & Num Sched & Num Seized & $\underline{\text { Sched Util }}$ \\
\hline $\begin{array}{l}\text { Ajudante } \\
\text { Conferente } \\
\text { Motorista }\end{array}$ & $\begin{array}{l}0,94 \\
0,24 \\
0,71\end{array}$ & $\begin{array}{l}0,94 \\
0,24 \\
0,71\end{array}$ & $\begin{array}{l}1,00 \\
1,00 \\
1,00\end{array}$ & $\begin{array}{l}43,00 \\
38,00 \\
29,00\end{array}$ & $\begin{array}{l}0,94 \\
0,24 \\
0,71\end{array}$ \\
\hline
\end{tabular}

Fonte: Elaborado pelos autores

A partir deste cenário, foi proposto o aumento de um funcionário para ajudar na realização dos processos de separação/descarga e guardar produto, um segundo ajudante vai ser inserido na simulação no intuito de eliminar os gargalos nos processos citados anteriormente.

A fila apresentada na primeira simulação de acordo com a Figura 5 diminuiu consideravelmente, fazendo com que os processos trabalhem de maneira mais eficiente.

A Figura 5 e a Figura 6 mostram, respectivamente, os relatórios de quantidade de filas, e a utilização de recursos. Neles, pode-se notar que no processo de separação/descarga, a fila é de 35.25, na descarga há apenas um (motorista) e 38.49 na descarga 2 (ajudante). 
Figura 7 - Simulação de melhoria no software ARENA

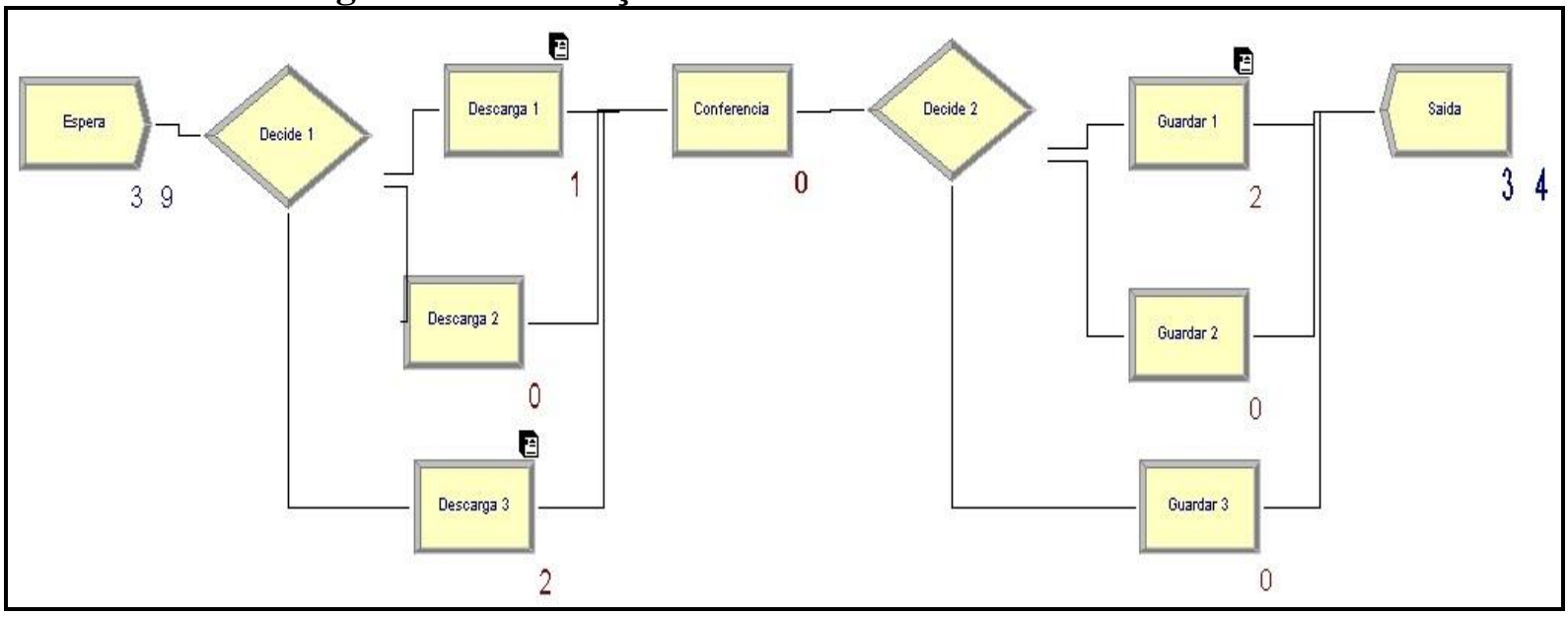

Fonte: Elaborado pelos autores

Já no processo de guardar os produtos a fila é de 23.09 para guardar 1(motorista) e 40.29 para guardar 2 (ajudante). Será visto nas duas próximas figuras que a adição de um ajudante para ajudar nos processos em destaque e nos demais processos, surtiram efeito, fazendo com que os processos fossem otimizados ajudando na redução das filas e tempos, conforme a Figura 8, no relatório de filas (Queues) do software ARENA, e promovendo uma melhor utilização dos 3 funcionários em estudo (motorista, ajudante 1 e ajudante 2), como mostra o relatório resources da figura 9.

Observando a Figura 8, pode-se entender que o tempo de espera no processo foi distribuído entre os 3 funcionários presentes no processo, diminuindo o tempo gasto e otimizando os processos em discussão.

Figura 8 - Relatório de filas (Melhoria)

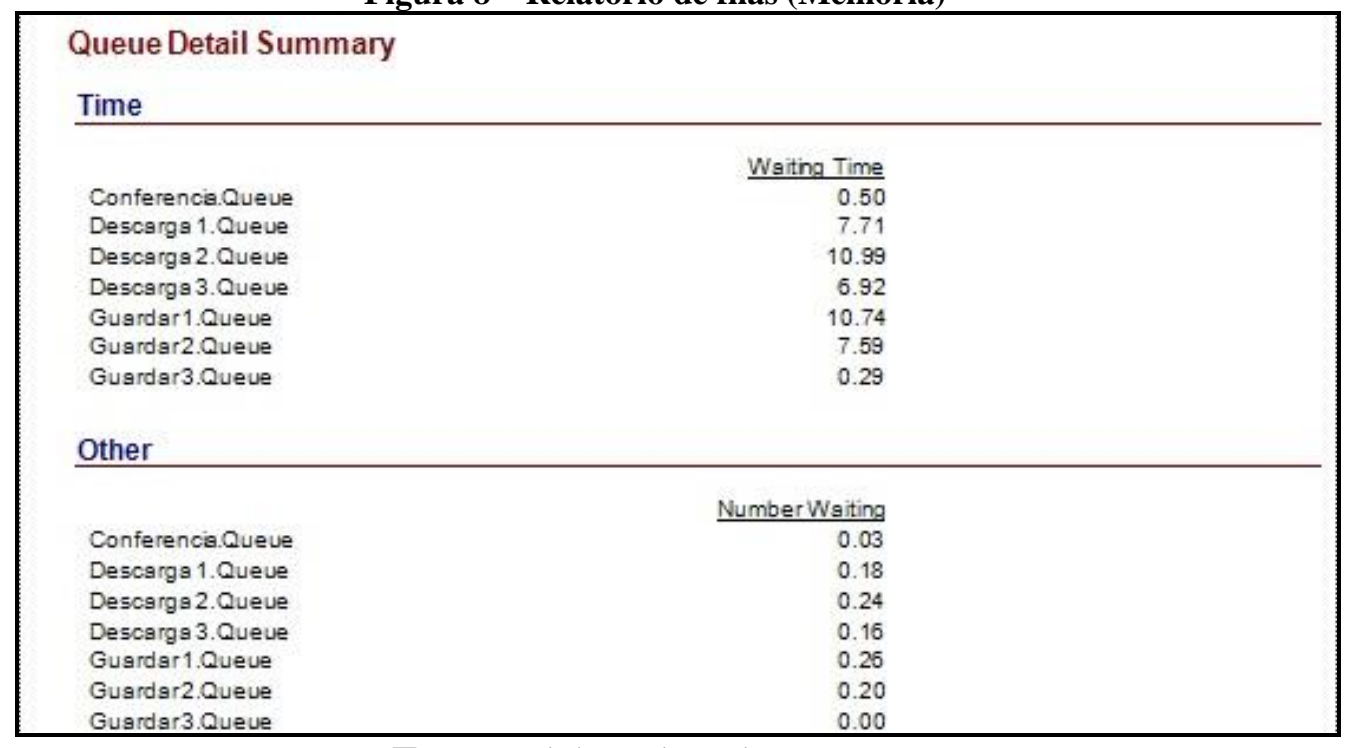

Fonte: Elaborado pelos autores 
Os processos ficam mais dinâmicos e rápido, distribuindo as tarefas entre os funcionários sem deixar nenhum com ociosidade, pois, com o incremento do Ajudante 2 (utilizado 49\%), de 94\% de utilização do Ajudante, sua utilização foi reduzida para 69\%, como pode se ver na Figura 9.

Figura 9 - Relatório de Recursos (Melhoria)

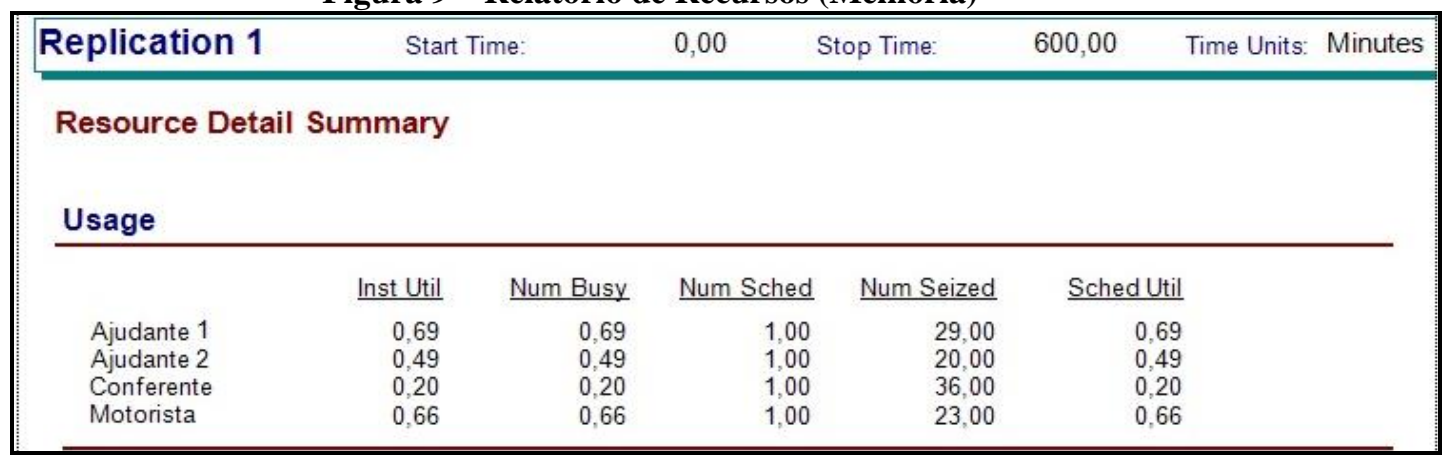

Fonte: Elaborado pelos autores

\section{CONSIDERAÇÕES FINAIS}

Conclui-se que, ao se utilizar o software ARENA, pode-se identificar o gargalo dos processos de separação/descarga e guardar produto.

A solução encontrada foi adicionar mais 1 funcionário (ajudante 2) para aumentar a otimização dos processos com maior índice de filas e assim diminuir o gargalo.

Mesmo com o acréscimo de mais um funcionário, é possível visualizar uma pequena fila no processo, e se conclui que não há necessidade de um novo funcionário, o acréscimo de 1 novo já ocorreu uma melhoria significativa.

Portanto, o software ARENA auxiliou no processo de otimização dos processos, cumprindo com o objetivo do artigo, já que a empresa buscava uma redução dos tempos de entrega, com o intuito de diminuir e até zerar as horas extras do setor de transporte.

\section{REFERÊNCIAS}

BOWERSOX, D. J. \& CLOSS, D. J. Logística empresarial: o processo de integração da cadeia de suprimento. São Paulo: Atlas, 2001.

FLEURY, P. Gestão Estratégica do Transporte. 2002. Disponível em: Acesso em: 15 jan. 2010. 


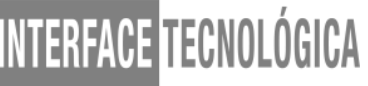

MICHAELIS. Dicionário Brasileiro da Língua Portuguesa. 2016. Disponível em:

$<\mathrm{http}: / /$ michaelis.uol.com.br/busca? $\mathrm{r}=0 \& \mathrm{f}=0 \& \mathrm{t}=0 \&$ palavra=simular $>$. Acesso em: 26 de jul. de 2016

OLIVEIRA, L. H.; SENA, R. V. Impacto da sofisticação no padrão de prestação de serviços logísticos oferecidos pelas empresas de transporte de cargas de Minas Gerais. In: XXXI ENCONTRO DA ASSOCIAÇÃO NACIONAL DE PÓS-GRADUAÇÃO E PESQUISA EM ADMINISTRAÇÃO - ENANPAD. Anais... Rio de Janeiro: ANPAD, 2007.

PARAGON. Introdução à Simulação com ARENA. São Paulo, SP: ENEGEP, 2005.

PARAGON. ARENA. Disponível em: <https://www.paragon.com.br/en/softwares-en/arenaen/>. Acesso em: 05 maio 2019.

PEDGEN, C. D., SHANNON, R. E., SADOWSKI, R. P. Introduction to Simulation Using SIMA., McGraw-Hill, New York, USA. v. 2. 1990.

PRADO, D. S. Usando o ARENA em simulação. 5. ed. Belo Horizonte: Falconi, 2014. 